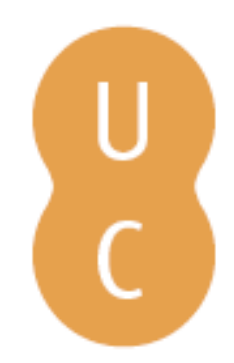

\title{
pommalina
}

\section{Marcas dentárias em alimentos e na pele}

Autor(es): $\quad$ Corte-Real, Ana; Oliveira, Carina; Marques, Jeidson; Vieira, Duarte Nuno

Publicado por: Imprensa da Universidade de Coimbra

URL

persistente: URI:http://hdl.handle.net/10316.2/38417

DOI: $\quad$ DOI:http://dx.doi.org/10.14195/978-989-26-0963-8_4

Accessed : $\quad$ 26-Apr-2023 11:10:21

A navegação consulta e descarregamento dos títulos inseridos nas Bibliotecas Digitais UC Digitalis, UC Pombalina e UC Impactum, pressupõem a aceitação plena e sem reservas dos Termos e Condições de Uso destas Bibliotecas Digitais, disponíveis em https://digitalis.uc.pt/pt-pt/termos.

Conforme exposto nos referidos Termos e Condições de Uso, o descarregamento de títulos de acesso restrito requer uma licença válida de autorização devendo o utilizador aceder ao(s) documento(s) a partir de um endereço de IP da instituição detentora da supramencionada licença.

Ao utilizador é apenas permitido o descarregamento para uso pessoal, pelo que o emprego do(s) título(s) descarregado(s) para outro fim, designadamente comercial, carece de autorização do respetivo autor ou editor da obra.

Na medida em que todas as obras da UC Digitalis se encontram protegidas pelo Código do Direito de Autor e Direitos Conexos e demais legislação aplicável, toda a cópia, parcial ou total, deste documento, nos casos em que é legalmente admitida, deverá conter ou fazer-se acompanhar por este aviso. 


\section{IDENTIFICAÇÃO EM MEDICINA DENTÁRIA FORENSE}

ANA CORTE-REAL DUARTE NUNO VIEIRA COORDENAÇÃO 


\title{
Capítulo IV
}

Marcas dentárias em alimentos e na pele

Considerações históricas

Mecanismo de mordida/mordedura

Descrição de uma mordida em pele

Metodologia - segundo as normas da ABFO

Preservação das evidências

Observação e registo da evidência

\author{
Ana Corte-Real \\ Carina Oliveira \\ Jeidson Marques \\ Duarte Nuno Vieira
}




\section{RESUMO:}

As terminologias mordedura, mordida ou bitemark são sinónimas e referem-se à marca resultante da ação dos dentes na pele humana, animal ou num substrato deformável. Cada dentadura é singular, sendo que o seu tamanho, a forma, o alinhamento, as rotações, os diastemas ou as restaurações, são, entre várias outras, características suscetíveis de poderem atribuir à mordida um valor probatório na identificação. Contudo, um mesmo indivíduo pode provocar mordidas distintas em função de diversas variáveis. Assim sucede, por exemplo, com a superfície corporal, o tipo de alimento atingido, a idade e o género da vítima, bem como a intensidade utilizada no ato de morder. Os parâmetros escolhidos para a interpretação, descrição e análise de uma mordida devem ser facilmente aplicáveis no período ante ou post mortem.

\section{PALAVRAS-CHAVE:}

mordida, características individualizantes, análise métrica, análise morfológica.

\section{ABSTRACT:}

The terminologies bite and bitemark are synonymous and refer to marks resulting from the action of teeth on skin (human or animal) or on a deformable substrate. Each denture is unique in size, shape, alignment, rotations, diastema and restorations, among others. These characteristics may attach to a bite a probative value in identification. However, the same individual may cause distinct bites depending on several variables such as body surface area, type of food reached, the age and gender of the victim, as well as the severity of the act of biting. The chosen parameters for the interpretation, description and analysis of a bite should be easily applied in ante or post mortem period.

\section{KEYWORDS:}

bitemark, individualizing characteristics, metric analysis, morphological analysis. 


\section{IV.1. INTRODUÇÃO}

Mordida, mordedura, dentada, bitemark ou bite mark, são palavras sinónimas, correspondentes ao registo total ou parcial, provocado pelos dentes e tecidos circundantes, designadamente a língua e os lábios. Refletem o papel das relações interdentárias e respetivas arcadas no ato de morder, que resulta numa alteração física do meio, produzindo marcas e lesões, pelo contacto humano ou animal, na pele de indivíduos vivos, cadáveres ou em objetos inanimados relativamente moles [1-4]. Para meIhor sistematização, considera-se a designação «mordedura» como o ato ou efeito de morder em objeto e a designação de «mordida» quando em pele humana.

O arco dentário de cada indivíduo é único, em virtude das suas múltiplas características individualizantes, como sejam, por exemplo, as perdas dentárias, fraturas, restaurações, cáries, tratamentos endodônticos, tratamentos protéticos fixos, sedes de apoio para próteses removíveis, doenças periodontais, tratamentos ortodônticos, largura e comprimento do arco e mau posicionamento dos dentes, entre outras. Quanto maior o número de características dentárias singulares de um arco dentário, maior a probabilidade de correlação com um suspeito e maior a individualidade da mordida. Nesta conformidade, as marcas provocadas pela ação dos dentes são, pois, achados de inquestionável interesse no sistema judicial, passíveis de correlacionar uma evidência física com um determinado suspeito [2-7].

\section{IV.2. CONSIDERAÇÕES HISTÓRICAS}

Pode considerar-se existirem dois períodos no historial da utilização forense de marcas dentárias, separados pela publicação de 1984, contendo orientações classificativas, do American Board of Forensic Odontology (ABFO) [2]. Na realidade, a uniformização de critérios não era possível antes desta data [2], sendo até então os resultados apresentados consoante a interpretação individual de cada profissional.

As normas criadas pela ABFO permitiram estabelecer uma metodologia no que se refere à identificação, registo, análise de mordidas, como uma interpretação dos resultados obtidos e suscetível de constante atualização técnico-científica. Esta harmonização metodológica conduziu a um rápido desenvolvimento da Medicina Dentária no âmbito da investigação forense $[2,4,5]$ e permitiu maximizar a qualidade, integridade e validade de uma colheita, bem como interpretar uma prova e obter um resultado [2].

A interpretação dos resultados da análise de mordidas é predominantemente descritiva e consequentemente qualitativa. Existe, contudo, a relevância da obtenção de um resultado quantitativo, face às necessidades e exigências dos tribunais, sendo tal possível em estudos prospetivos ou por associação à análise genética dos componentes da mordida. 


\section{IV.3. MECANISMO DE MORDIDA/ MORDEDURA}

As marcas e lesões resultantes do ato de morder são consequência da associação de dois componentes, designadamente das arcadas dentárias e da musculatura orofacial. Do movimento de fecho de ambas as arcadas resulta o registo das marcas dentárias.

A exuberância da impressão de mordida encontra-se relacionada com a musculatura labial, lingual e jugal, com o género e robustez física do indivíduo, bem como com o grau de violência da mordida. Neste aspeto, é de utilidade a escala de gravidade crescente de Pretty [3], em que as mordidas são descritas e classificadas em graus distintos: escoriações ou arranhões (grau 1), petéquias (grau 2), contusões ou hematomas (grau 3), abrasões (grau 4), lacerações (grau 5) e avulsões (grau 6).

No âmbito de produção da mordida destacam-se as agressões físicas de um modo geral e as infligidas no contexto de uma agressão de natureza sexual [4]. Estas últimas ocorrem maioritariamente no género feminino, observando-se habitualmente uma área equimótica central e localizando-se frequentemente nos seios, coxas e nádegas. Nas situações correspondentes a ataques ou defesa, a área equimótica central está normalmente ausente, surgindo sobretudo nas bochechas, nádegas, abdómen, dedos, orelhas e nariz das crianças. No que se refere à intenção de uma mordida, pode correlacionar-se o posicionamento de ambas arcadas dentárias no ato de morder. No âmbito de uma agressão de natureza sexual, a posição inicial de oclusão ou relação cêntrica origina maior confusão no detalhe das superfícies oclusais [4]. Por outro lado, há unanimidade em considerar que nas lesões de defesa, ocorre frequentemente a posição de protrusão mandibular ou topo-a-topo, resultando maior clareza na impressão das superfícies vestibulares coronárias dos dentes anteriores [4].

Ao considerar-se o mecanismo de mordedura aplicado a um alimento relativamente mole (por ex. pão ou bolo), a mandíbula efetua um movimento em protrusão com a interposição do alimento entre ambas as arcadas e os dentes superiores tendem a agarrá-lo enquanto os inferiores rasgam. Alimentos como o queijo, a maçã, o chocolate ou a pastilha elástica, são os mais encontrados na cena do crime, apresentando esta última grande capacidade de reprodução da face oclusal [4].

Ao considerar-se os dentes nas respetivas arcadas dentárias como intrumentos atuantes numa agressão, pode-se caracterizá-los em virtude da sua natureza ou da forma como atuam, na medida em que determinarão um ferimento contundente ou perfurocontundente $[2,5-7]$.

\section{IV.4. DESCRIÇÃO DE UMA MORDIDA EM PELE}

A pele é o orgão que reveste a superfície corporal e está organizada em três camadas, designadamente epiderme, derme e hipoderme.

No corpo humano a pele cumpre funções diversas: imunitária, de regulação térmica, nervosa, sensorial, metabólica, destacando-se no âmbito do tema em apreço, a sua função protetora em relação a agressões físicas.

A epiderme é responsável pelo bloqueio ao trânsito centrípeto das radiações (pela presença de 
melanina) e fluídos (pela presença de queratina) e no sentido centrífugo pelo bloqueio da desidratação (contribuição das glândulas sebáceas). Em virtude da sua enorme vascularização e riqueza em fibras, nutrição e termorregulação, a derme correlaciona-se com a elasticidade e sustentabilidade da epiderme.

A função protetora da pele encontra-se relacionada com a epiderme e derme, podendo ocorrer simultaneamente perante uma agressão, processos de inflamação e de reparação [8].

A agressão resultante de uma mordida pode ocorrer no período ante mortem e originar um ferimento vital. Podem considerar-se existir três fatores dimensionais implícitos numa mordida, designadamente, a curvatura da pele, a forma das arcadas dentárias do agressor e a profundidade da lesão resultante $[4,7,8]$. Pela combinação destes fatores resulta a deformação da pele de modo a «acomodar» a forma do(s) dente(s). Após a supressão da fonte agressora (os dentes) ocorre uma reação da pele à agressão, no contexto de um processo de reparação tecidular, cujo objetivo é recuperar a forma original da superfície $[7,8]$. Quando o mesmo tipo de agressão se verifica num período post mortem não há reparação tecidular e a mordida é mais fidedigna quanto ao registo das formas anatómicas. As crianças, os idosos e os indivíduos do género feminino geralmente apresentam uma pele mais sensível, que se lesiona com maior facilidade comparativamente com indivíduos do género masculino jovens e adultos [4].

Quanto às características de uma mordida estas podem ser classificadas em dois grupos distintos: os inerentes ao padrão de uma agressão, que pressupõe a atribuição da gravidade lesional, e os inerentes à especificidade anatómica e funcional das arcadas dentárias do suspeito agressor (características individualizantes).

Relativamente ao primeiro grupo, o ferimento deverá ser caracterizado pelas alterações macro e microscópicas dos tecidos envolventes. Como as referidas lesões são usualmente avaliadas algum tempo após o ato de morder, as características fisiológicas inerentes ao processo inflamatório devem ser consideradas no âmbito das alterações anatómicas e colorimétricas da pele. Na presença de múltiplos ferimentos, a avaliação deste grupo permite datar o intervalo temporal entre eles. No que concerne à mordida deve ser mencionada a sua localização topográfica e severidade [2,3], uma vez que esta última se relaciona diretamente com a sua importância médico-legal. Uma mordida difusa dificilmente conduz a uma identificação positiva do agressor, na medida em que não apresenta pormenores suficientes quanto ao número de características individualizantes. Uma mordida severa e agressiva permite uma maior seleção de possíveis agressores. Uma mordida associada a arrancamento tecidular, com necessidade de assistência médica em virtude da sua severidade, é de difícil descrição morfológica e de possibilitar, per si, uma identificação positiva do agressor.

Assim sendo, uma mordida pode ser descrita como uma lesão circular ou oval, constituída por dois arcos simétricos, separados nas extremidades. Na periferia desses arcos podem encontrar-se formas idênticas a abrasões e lacerações [2].

No que se refere ao segundo grupo, a avaliação da forma da lesão encontra-se relacionada com o tipo de dente em causa. A forma linear ou retangular de uma contusão reflete o bordo oclusal dos dentes incisivos, estando a sua maior dimensão relacionada com o tipo de dente (central 
ou lateral, definitivo ou decíduo). Por outro lado, o tamanho e a forma da lesão podem categorizar uma arcada dentária de dentição decídua versus definitiva e a sua correspondência ou não a uma mordida humana. Os dentes envolvidos são essencialmente os primeiros cinco dentes de cada quadrante (incisivos, caninos e prémolares). Os dentes molares, devido à sua localização posterior na cavidade oral, raramente estabelecem contato com a pele ou alimento; nos dentes posteriores são tomadas as referências das cúspides vestibulares $[2,4,9]$.

Destacam-se o número, a especificidade e a correta reprodução das características individualizantes, quer unitárias quer em conjunto, que contribuem para a determinação precisa do suspeito.

A qualidade descritiva de uma mordida está intimamente relacionada com o maior número de características dentárias individualizantes que podem ser observadas, mensuradas e comparadas [4-9].

\section{IV.5. METODOLOGIA - SEGUNDO AS NORMAS DA ABFO}

A identificação e análise de mordidas devem obedecer a um procedimento metódico, rigoroso e reprodutível. A metodologia preconizada pela ABFO compreende o cumprimento de várias etapas que se passa a descrever [2].

\section{IV.5.1- PRESERVAÇÃO DAS EVIDÊNCIAS}

Obtida a autorização legal para a aplicação da metodologia de análise, devem ponderar-se todos os fatores ambientais (designadamente o calor e a humidade) e de origem humana (os processos de conservação do cadáver ou alteração de posição do mesmo) que podem mascarar e comprometer a correta observação e registo da evidência [2].

Em virtude do risco de contaminação deve ser considerada a possibilidade de realização de colheitas para exames complementares, nomeadamente de análise genética.

\section{IV.5.2 - OBSERVAÇÃO E REGISTO DA EVIDÊNCIA}

\section{- Observação}

No que se refere ao exame objetivo deverão ser considerados diversos aspetos, nomeadamente, a identificação e datação do exame pericial, o registo da forma, cor, tamanho e localização topográfica da lesão de mordida, a caracterização dos tecidos e da superfície circundante, bem como o tipo de lesão (abrasão, contusão, avulsão) e informações adicionais (condição específica, exames complementares, pedidos efetuados).

\section{- Fotografia}

Devem ser efetuadas fotografias, in situ, com enquadramento geral e em close-up de modo a auxiliar a observação a "olho nú», bem como registar e conservar os detalhes para posterior avaliação (figs. IV.1). De modo a obterem-se fotografias com alta definição recorre-se preferencialmente a sensores full-frame, num ficheiro RAW, a cores e assegurando a aplicabilidade do balanço dos cinzentos [8]. 

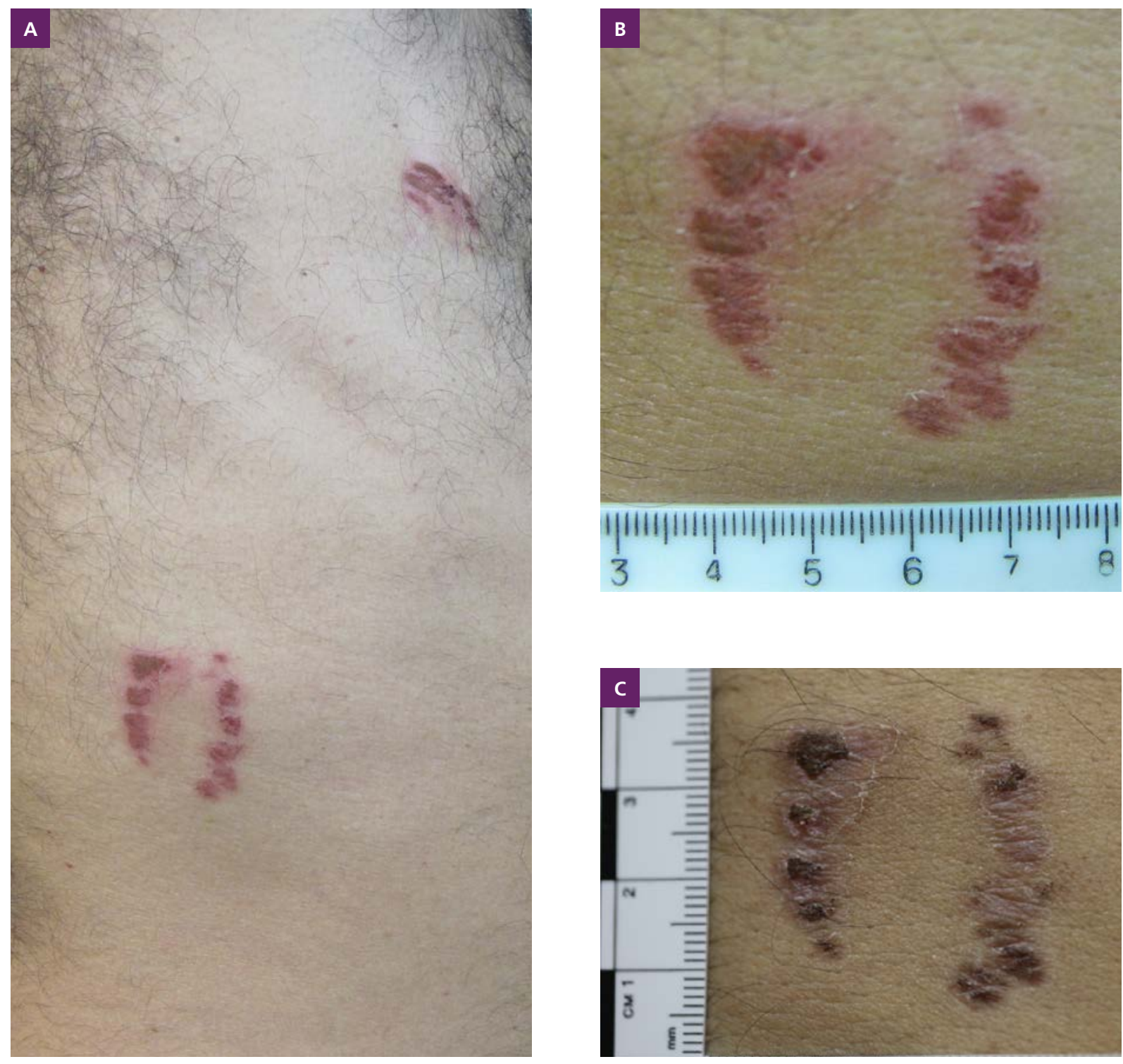

Figuras IV.1 (A, B e C) - Registos fotográficos de lesões sugestivas de marcas dentárias. (A) Plano geral. (B) Em close-up. (C) Em close-up após 8 dias decorridos do traumatismo. Cortesia do INMLCF, I.P 2013. 


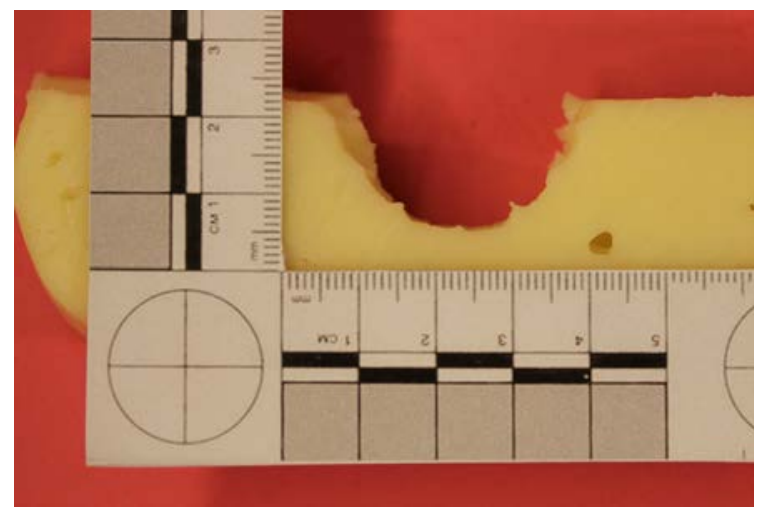

Figura IV.2 - Registo fotográfico com escala ABFO n², de fragmento de queijo com marcas da arcada dentária superior.

A fotografia de close-up deve ser obtida com e sem escala, de forma a permitir o registo da totalidade da zona. A escala métrica (tipo ABFO $n^{\circ} 2$ ) deve localizar-se no mesmo plano e em posição adjacente às marcas de mordida (fig. IV.2).

Além da radiação visível pode ser utilizada a radiação ultravioleta, bem como um filme com uma sequência de imagens obtidas em vítimas (figs. IV.3).

\section{- Reprodução da evidência}

A reprodução da mordida pode ser realizada pela sua impressão, com obtenção do negativo, ou por leitura computorizada da superfície e obtenção de imagens tridimensionais.

A técnica de impressão exige que os materiais de moldagem sejam preparados de acordo
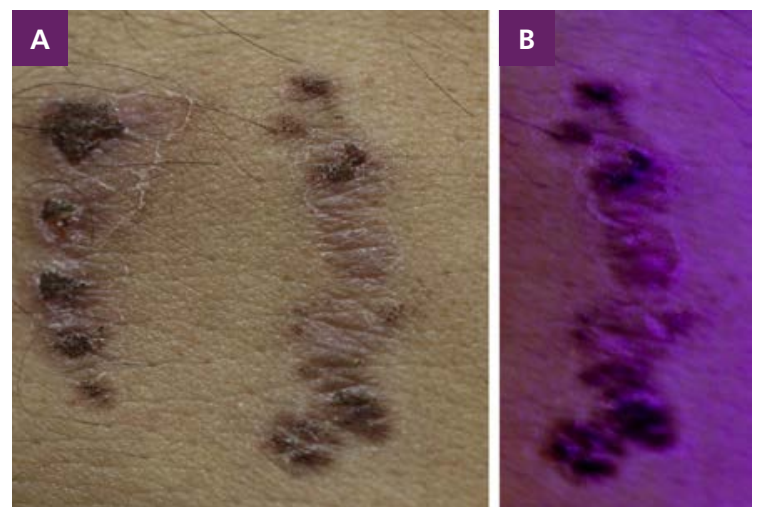

Figuras IV.3 (A e B) - (A) Registo fotográfico com exposição a radiação visível. (B) Registo fotográfico com exposição a radiação UV, destacando uma melhor visualização dos contornos da lesão. Cortesia do INMLCF, I.P. 2013.

com as normas do fabricante e obedeçam às especificações da ABFO. Nesta técnica deverá ser igualmente reproduzida a porção de superfície não atingida pela lesão de mordida. Em tecidos mortos as impressões devem ser conservadas, sempre que possível, em material que possibilite a sua inalterabilidade, como acontece na técnica de transiluminação [7].

As impressões devem ser efetuadas em material dentário resiliente (tipo Eramix por GC Co.), passadas a gesso pedra tipo III (usualmente utilizado para modelos de estudo, com expansão de presa de 0,10 a 0,18\% e resistência à compressão de $281 \mathrm{~kg} / \mathrm{cm}^{2}$ ) e finalmente em máquina de vácuo (tipo Vac-U-Spat).

Uma análise de mordida deverá ser tridimensional de modo a registar todos os aspetos lesionais. Este tipo de análise tem vindo a ser 


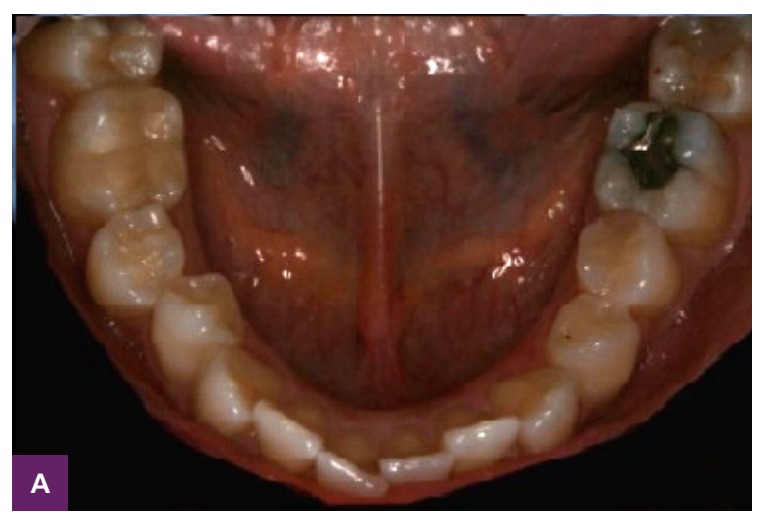

Figura IV.4 (A, B e C) - Registos fotográficos da arcada dentária inferior do suspeito: (A) intra-oral, (B) do modelo de gesso em vista oclusal e (C) do modelo de gesso em vista frontal.

divulgada cientificamente em situações de difícil impressão ou quando há risco de danificação da amostra [10]; neste sentido procura-se a validação do registo de mordida como prova pericial em processo judicial $[8,11]$.

\section{IV.5.3. - O SUSPEITO: REGISTO E REPRODUÇÃO DE DADOS}

A descrição do exame dentário do suspeito, incluindo a informação circunstancial relativa ao evento traumático (mordida), é também elemento de particular relevância neste contexto.

O exame extraoral inclui a observação e interpretação da dinâmica da articulação
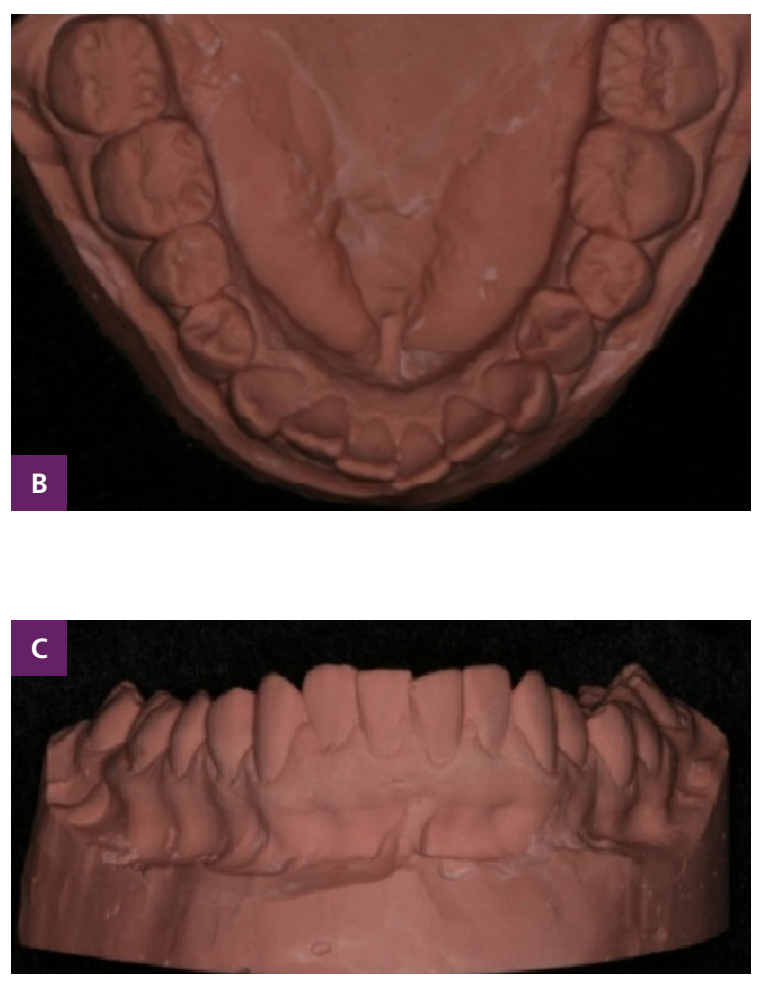

temporomandibular, ou seja, a análise funcional da articulação que permite avaliar as assimetrias faciais nos movimentos mandibulares. No movimento de abertura e fecho deve ser efetuada a medição da abertura máxima e dos desvios mandibulares, quando existentes. A análise da face deve obedecer às orientações descritas no Capítulo I e as fotografias devem abranger os planos frontal e de perfil.

O exame intraoral em relação cêntrica deve ser acompanhado de fotografias que incluam os planos oclusal, frontal e de perfil de cada arco, até aos primeiros molares, uma vez que apresentam aspetos individualizantes de elevada relevância (fig. IV.4). 

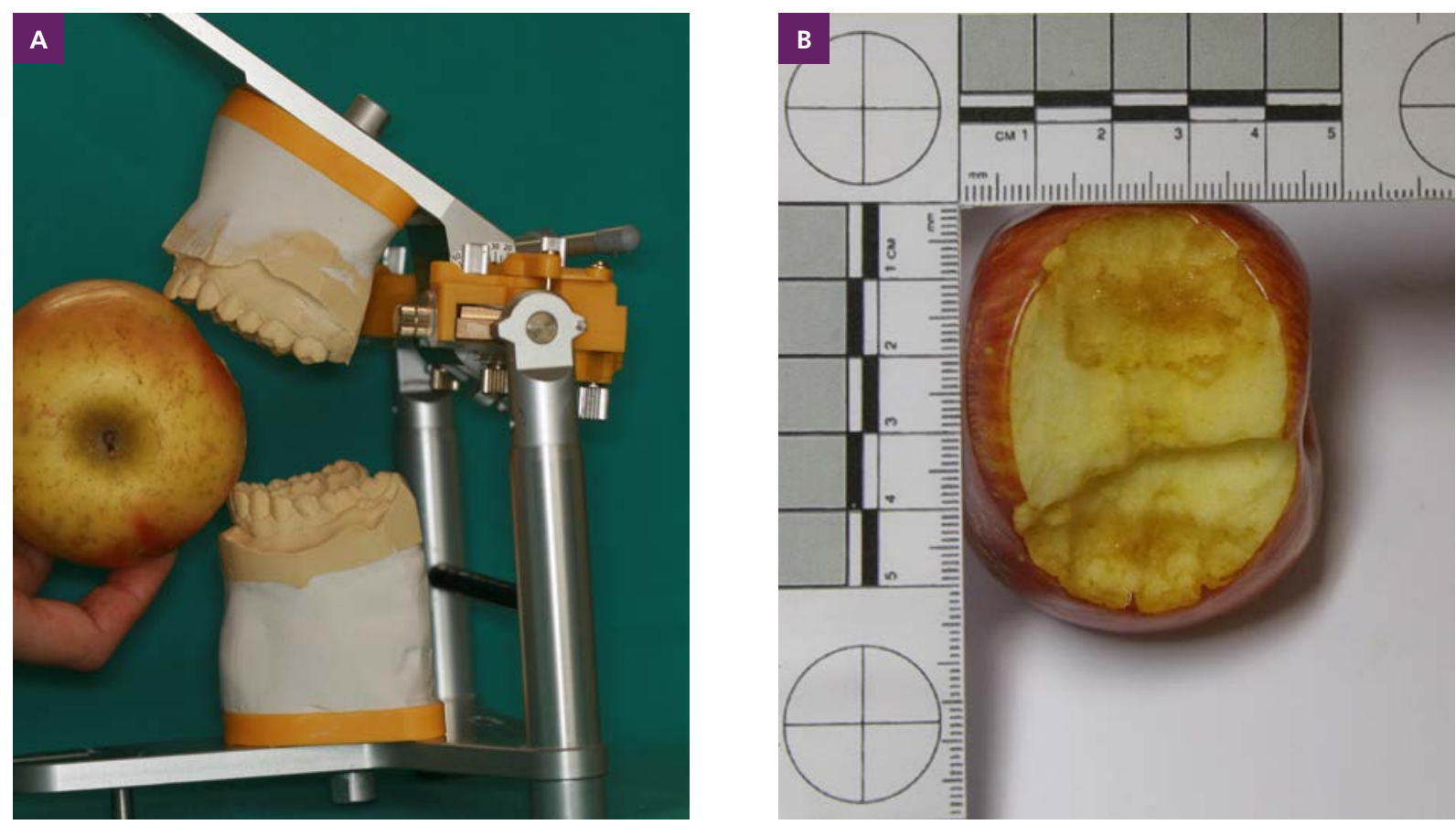

Figuras IV.5 (A e B) - Análise do ato de morder. (A) Arcadas dentárias do suspeito em articulador semi-ajustável tipo SAM2PXTM. (B) Fotografia do registo de marcas dentárias na maçã com escala ABFO n².

O exame da língua não deve ser esquecido e a sua dimensão ou qualquer alteração deve ser analisada, nomeadamente, a anquiloglossia e a existência de um freio lingual curto que limita os movimentos linguais.

É ainda pertinente a análise da condição periodontal, pela eventual existência de mobilidade dentária, áreas inflamadas ou de hipertrofia gengival com recobrimento parcial da coroa do dente.

Quanto à reprodução por impressão devem realizar-se duas impressões de cada arcada dentária com posterior construção do modelo em gesso pedra tipo III e um registo interoclusal. Os arcos dentários dos suspeitos devem ser montados num articulador semi-ajustável que permite avaliar o comportamento intermaxilar (figs. IV.5).

No local da mordida, a colheita de saliva e de células epiteliais do suspeito é um procedimento usual na determinação do perfil genético do mesmo. A técnica de colheita deste vestígio biológico consiste na realização de uma dupla zaragatoa, que no caso dos alimentos deverá ser efetuada nos limites das marcas dentárias, enquanto na pele deverá incluir igualmente o interior da lesão [12]. 

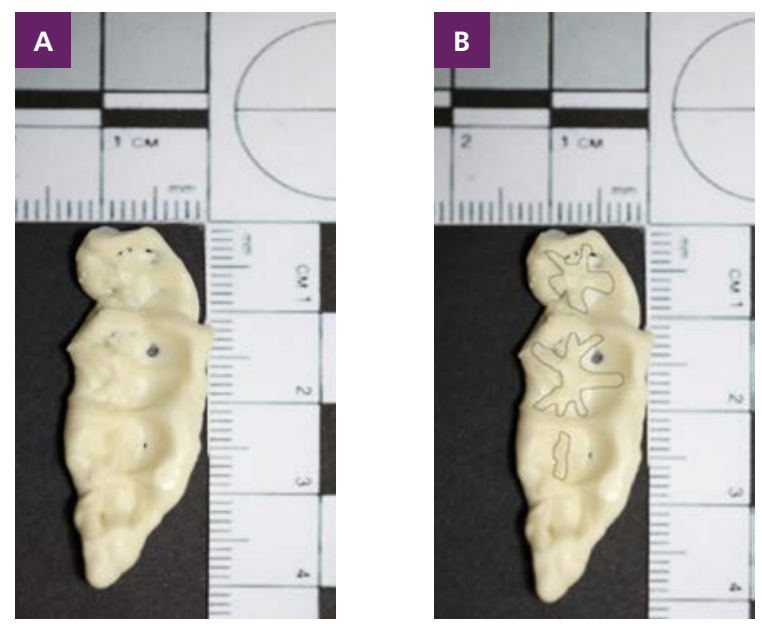

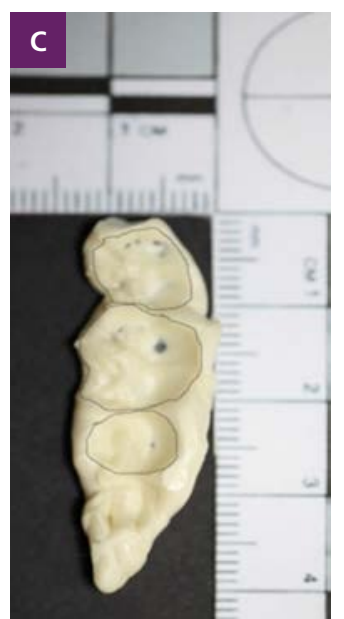

Figuras IV.6 (A, B e C) Registo fotográfico para análise pericial.

(A) Fotografia da prova com escala $\mathrm{ABFO} n^{\circ} 2$.

(B) Registo em profundidade dos detalhes anatómicos dos dentes posteriores numa pastilha elástica mascada.

(C) Registo em superfície, em relação com os detalhes de maior contorno das peças dentárias assinaladas.

\section{IV.5.4. - ANÁLISE DA MORDIDA}

A análise de registos de mordida tem sido controversa e tem sofrido constantes reajustes ao longo dos tempos $[2,6]$. Inicialmente este estudo baseava-se em parâmetros subjetivos [7] e a publicação de artigos científicos era escassa; no entanto, com a implementação da ABFO em 1984, surgiram as primeiras normas, que foram posteriormente revistas [8].

Os dados utilizados podem ser obtidos a partir de modelos de gesso, de radiografias efetuadas com material radiopaco aplicado à mordida em cera, do decalque das marcas em transparências, de fotografias das marcas, de técnicas de transiluminação, por estereoscopia (macro ou microscopia) e ainda por análise histológica. Todos esses dados são valorados quando comparados com os obtidos no suspeito.
Na análise das marcas de uma mordida efetua-se uma comparação anatómica e métrica dos dados obtidos na vítima com os do suspeito através de uma sobreposição manual ou por computador.

Pelo exposto, a análise de uma mordida é um estudo comparativo entre as características do suspeito e da vítima; em cada um deles, estuda-se a sua relação tridimensional [5]. Por analogia podemos considerar que a normalidade dos indivíduos têm dois olhos, duas orelhas, uma boca e um nariz, que permitem distinguir e reconhecer cada indivíduo como «único», pela relação existente entre essas características, como sejam, por exemplo, a relação existente entre o nariz e a boca, a posição das orelhas e dos olhos.

A metodologia de análise de uma mordida pode ser realizada através da associação da análise métrica (figs. IV.6), morfológica, de imagens tridimensionais (figs. IV.7) e estereoscópica. 

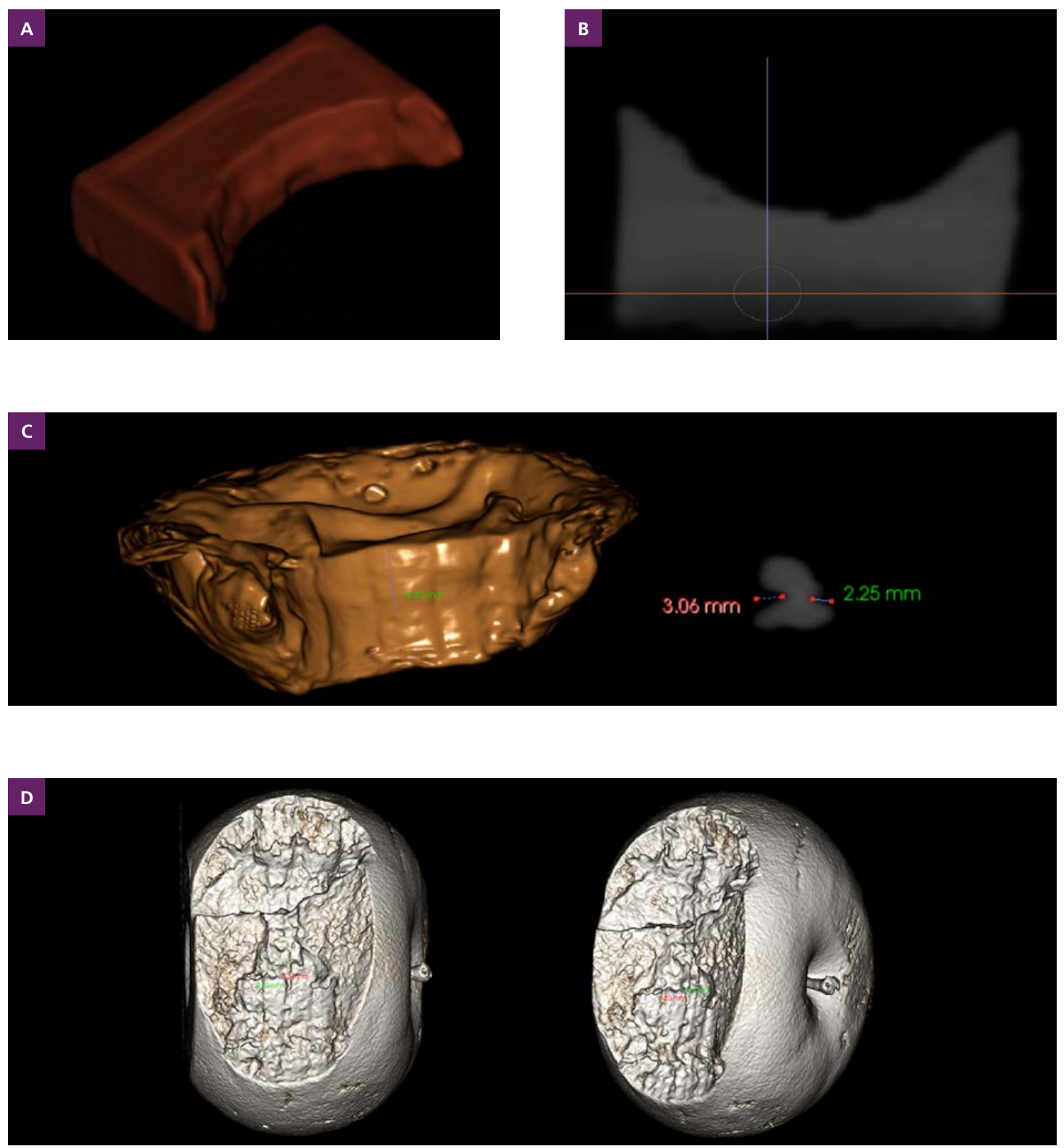

Figuras IV.7 (A, B, C e D) - Imagens DICOM de alimentos mordidos. (A) Reconstrução tridimensional do chocolate. (B) Corte tomográfico horizontal do chocolate, evidenciando a vestibularização do incisivo central inferior. (C) Reconstrução tridimensional do pastel de nata à esquerda, com mensuração da profundidade da mordida. À direita, corte sagital da pastilha elástica com mensuração da profundidade da mordida. (D) Reconstrução tridimensional de duas mordidas, do mesmo indíviduo no mesmo alimento, com mensuração mesio-distal do 31 e 32. Cortesia Catarina Caetano. 

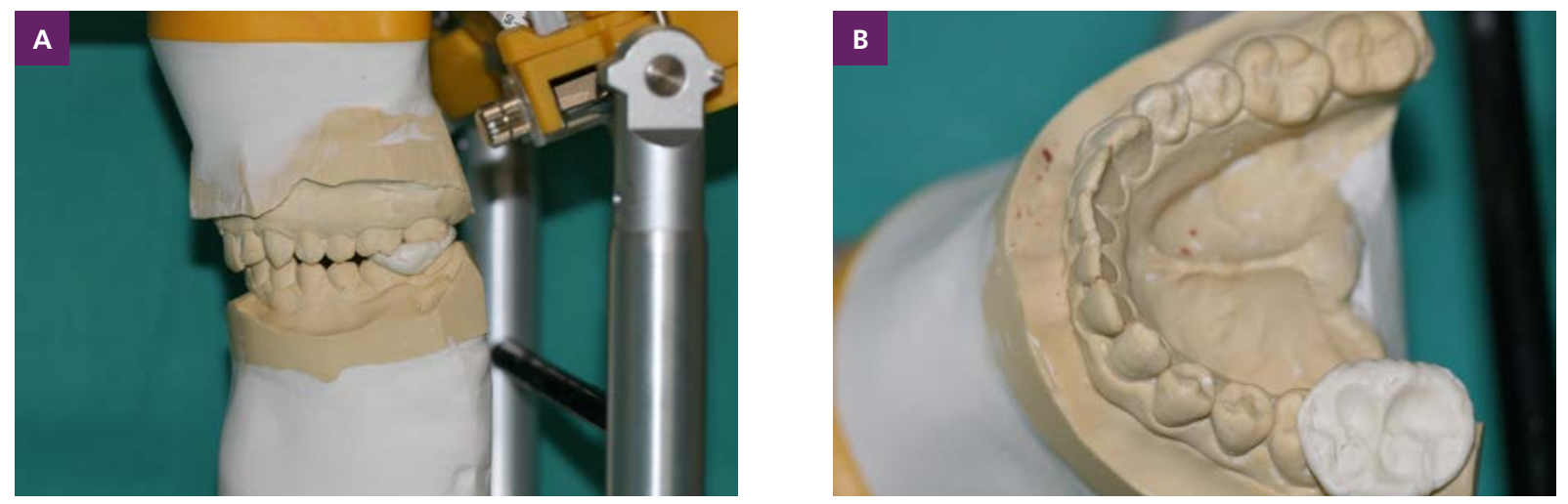

Figura IV.8 (A e B) - Fotografias das arcadas dentárias do suspeito, montadas em articulador para emparelhamento físico da prova. (A) com pastilha elástica mascada. (B) Visualização do emparelhamento da prova a nível dos dentes 36 e 37.

Na análise métrica, cada detalhe ou característica do dente do suspeito encontrado na mordida é medido e registado. Nesse estudo, considera-se o substrato onde ocorreu a mordida, a localização de ambas as arcadas e as respetivas peças dentárias envolvidas, o comprimento, largura e profundidade das marcas de cada dente (figs. IV.6 e IV.7), a distância máxima intercanina, as mensurações interdentárias, as indicações de incorreto posicionamento e ainda, a existência ou ausência de peças dentárias [4,9].

Destaca-se que a mensuração das odontometrias dentárias per si é insuficiente; crê-se essencial a pré-definição de coordenadas nas mordidas e nos modelos dentários e o estabelecimento de uma correlação entre ambas [10].
Considera-se que este procedimento permite estudar as distorções que podem eventualmente impossibilitar a análise física da mordida.

Em termos genéricos, existem dois tipos de distorções, primária e secundária. Os dois componentes principais da distorção primária encontram-se relacionados com a dinâmica do processo da mordida e com os aspetos particulares do objeto mordido, como, por exemplo, a quantidade de tecido biológico. A distorção secundária envolve três fatores, designadamente, o tempo decorrente desde o evento traumático (ato de morder) e a análise, a posição anatómica das estruturas dentárias e a execução técnica de reprodução, quer do registo manual, fotográfico ou da própria impressão $[9,13]$. Baseado no fator 

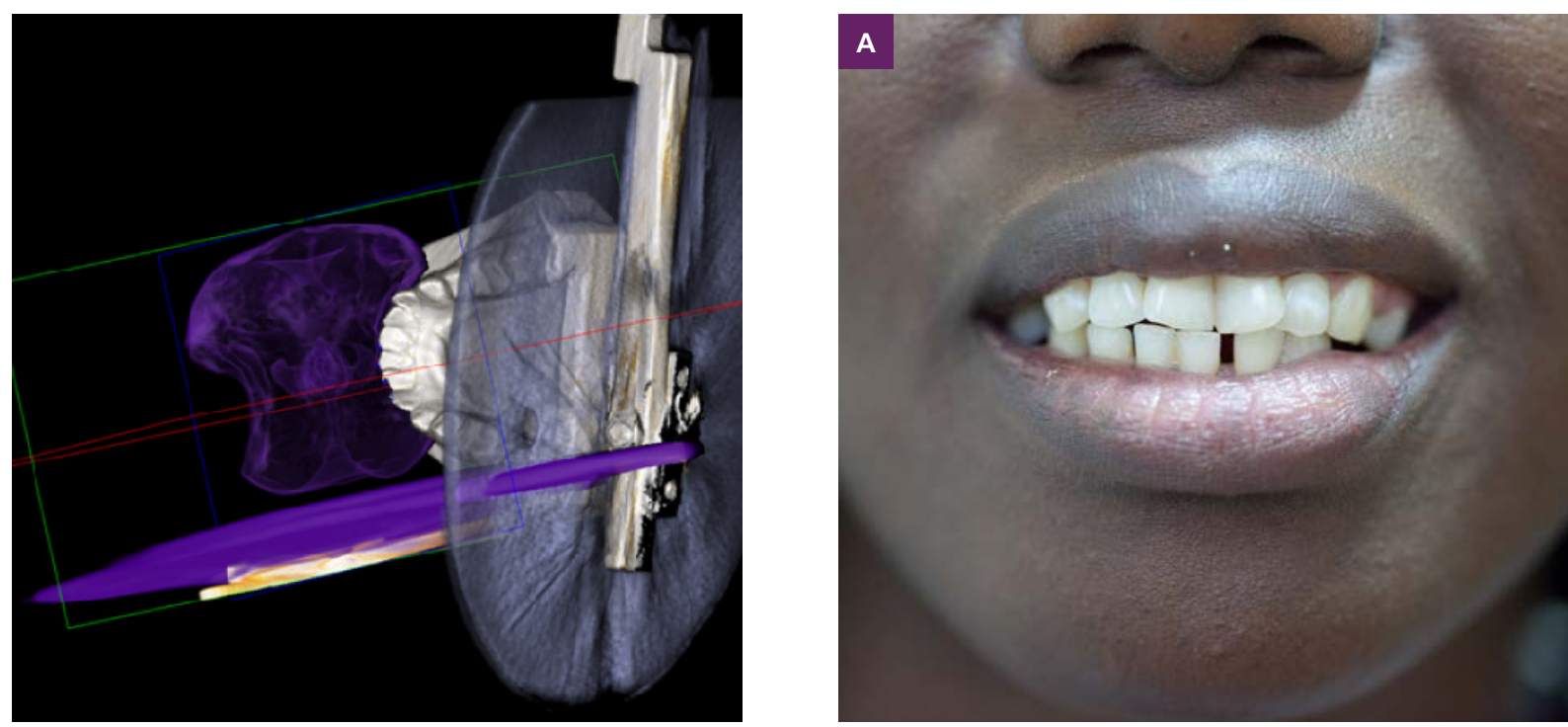

Figura IV.9 - Reconstrução tridimensional de prova e modelo do suspeito e respetiva análise morfológica por sobreposição.

tempo da distorção secundária assume-se que ao existirem três pontos na mordida em linha reta, eles permanecerão tendencialmente em linha reta, preservando os pontos médios e as relações de divisão segmentar, ainda que possa haver uma modificação na distância entre eles [14].

A análise morfológica considera o procedimento de sobreposição de imagens, correspondendo a um emparelhamento físico, que pode ser realizado de uma forma manual ou digital (figs. IV.6., IV.8, IV.9, IV.10) [13,15].

A análise estereoscópica considera o procedimento de sobreposição de duas imagens, correspondendo a um emparelhamento físico, que

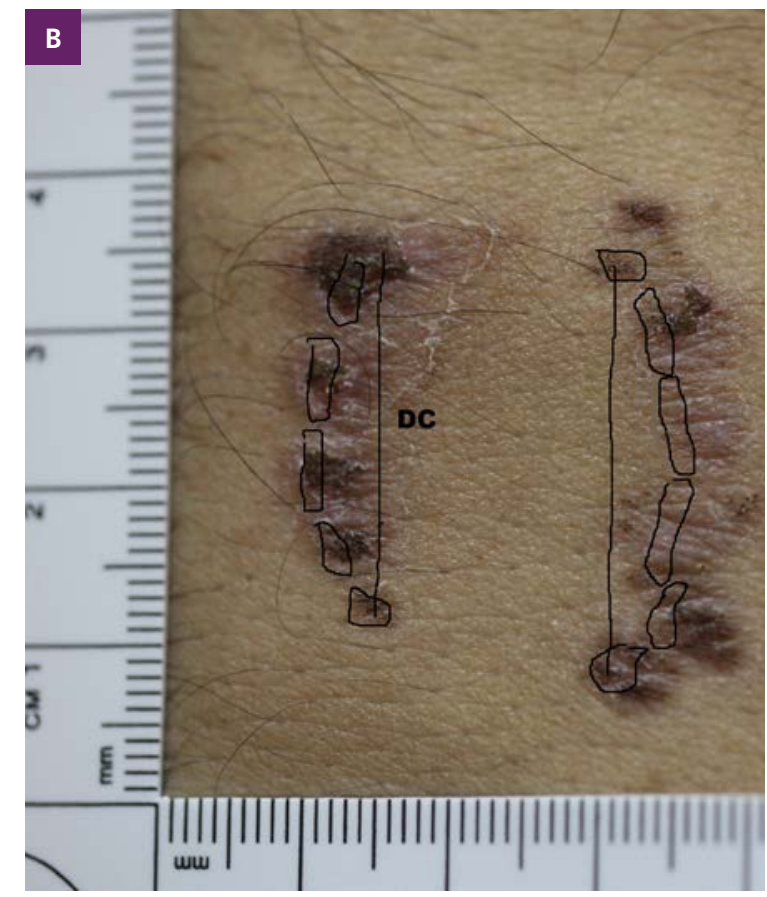

Figuras IV.10 (A e B) - Análise de mordida em pele. (A) Fotografia extraoral em PIM. (B) Registo fotográfico de uma mordida em pele, com o desenho dos dentes envolvidos e da distância intercanina (DC) superior (à direita) e inferior (à esquerda). Cortesia do INMLCF, I.P. 2013. 


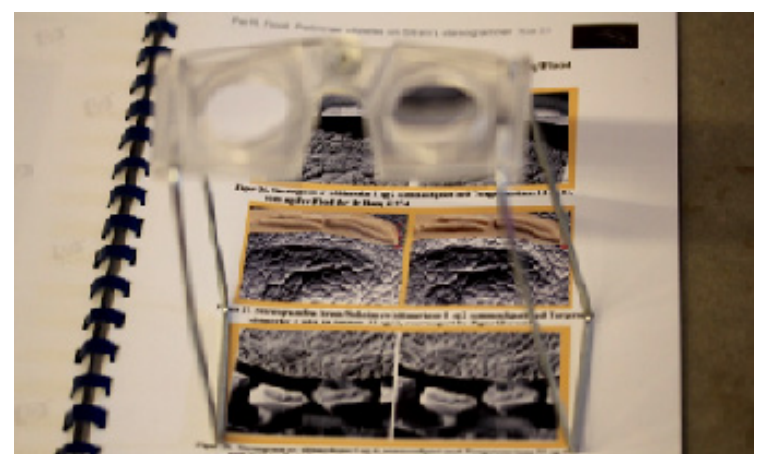

Figura IV.11 - Análise estereoscópica de marcas de mordidas, ajuste ocular sobre o registo fotográfico.

permite uma visão de profundidade do objeto (fig. IV.11).

A análise 3D considera o procedimento de comparação direta entre os arcos do suspeito e a superfície mordida, com visualização tridimensional (fig. IV.7, IV.9, IV.11, IV.12, IV.13).

\section{IV.5.5. - INTERPRETAÇÃO DOS RESULTADOS}

A interpretação dos resultados de uma mordida compreende a subdivisão de ambas as arcadas dentárias.

O resultado final corresponde à atribuição de uma das seguintes categorias, segundo as orientações da ABFO: The Biter, The Probable Biter, Not Excluded as the Biter, Excluded as the Biter ou Inconclusive. No entanto, a ABFO não suporta a conclusão «The Biter» em casos de população aberta [2].

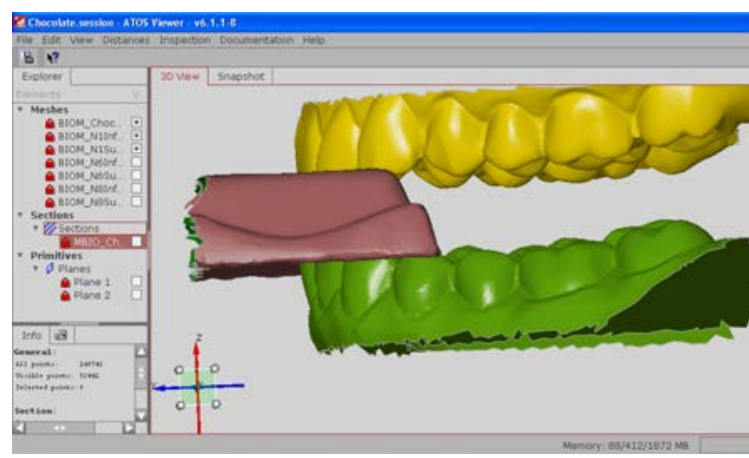

Figura IV.12 - Análise 3D de mordida em alimento, com arcos dentários do suspeito.

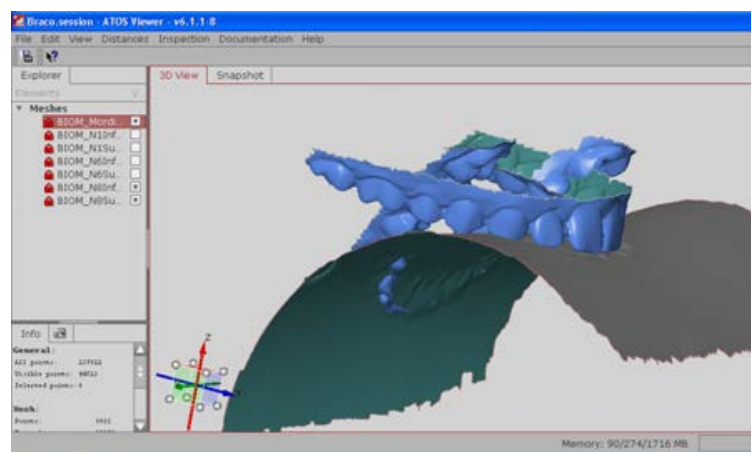

Figura IV.13 - Análise 3D de mordida na pele humana, com arcos dentários do suspeito.

\section{IV.5.6. - CONSIDERAÇÕES}

\section{- Mordida humana versus não humana}

Numa mordida humana, o registo compreende os dentes anteriores de ambas as arcadas dentárias, que originará uma impressão oval ou elíptica. A distância intercanina varia de $2,5 \mathrm{~cm}$ (na dentição decídua) a 4,5cm (na dentição definitiva). 
Por outro lado, na mordida não humana constata-se que a disposição, o volume e a morfologia dentárias são distintos comparativamente com a mordida humana [16].

\section{- Relação mordidas em alimentos versus pele}

As mordidas produzidas em alimentos rígidos (tipo queijo) são mais individualizantes, mais distintas entre si e mais correlacionadas com as arcadas dentárias do que as infligidas num substrato deformável, como a pele [6]. A dinâmica tecidular e a distorsão postural podem estar relacionadas com a qualidade da mordida na pele $[6,9,17-20]$.

\section{IV.6. REFERÊNCIAS}

[1] Kouble, F., Craig, T. (2007). A survey of the incidence of missing anterior teeth: Potential value in bite mark analysis. J For Sci, 47, pp.19-23.

[2] Bitemark Methodology Guidelines. (2013). American Board of Forensic Odontology, Inc. Diplomates Reference Manual, pp. 109-117.

[3] Pretty, I.A. (2007). Development and Validation of a Human Bitemark severity and significance scale. J For Sci, May, 52(3), pp.687-691.

[4] Marques, J.A.M., Galvão, L.C.C., Silva, M. (2007). Marcas de mordidas. Feira de Santana: Universidade Estadual Feira de Santana.

[5] Bernitz, H. (2005). Concepts to elucidate the patternassociated analysis of tooth marks in court. SADJ, Mar, 60(2), pp.62-65.

[6] Clement, J.G., Blackwell S.A. (2010). Is current bite mark a misnomer?. For Sci Int, 201, pp.33-37.

[7] Pretty, I.A., Asweet, D. (2010). A paradigm shift in the analysis of bitemarks. For Sci Int, 201, pp.38-44.

[8] Wright, F.D., Golden, G.S. (2010). The use of full spectrum digital photography for evidence collection and preservation in cases involving forensic odontology. For Sci Int, 201, pp.59-67.

[9] Blackwell, S.A., Taylor, R.V., Gordon I. e col. (2007). 3D imaging and quantitative comparison of human dentitions and simulated bite marks. Int J Legal Med, 121, pp.9-17.

[10] Lasser, A.J., Warnick, A.J., Berman, G.M. (2009). Threedimensional comparative analysis of bitemarks. J For Sci. May, 54(3), pp.658-661.

[11] Marques, J., Musse, J., Caetano, C. e col. (2013). Analysis of Bite Marks in Foodstuffs by Computed Tomography (Cone Beam (T) - 3D Reconstruction, J For Odontostomatol, ISSN:2219-6749, 31(1), pp.1-7.

[12] Corte-Real, A.T., Silva, D.N., Corte-Real, F. e col. (2013). Bitemarks in foodstuffs - An approach for genetic identification of the bitter. For Sci Int. Genetics Suppl Series 4, pp. e340-e341.

[13] Blackwell, S.A., Taylor, R.V., Gordon, I. e col. (2007). 3D imaging and quantitative comparison of human dentitions and simulated bite marks. Int J Legal Med, 121, pp.9-17.

[14] Stols, G., Bernitz, H. (2010). Reconstruction of deformed bite marks using affine transformation. J For Sci, May, 55(3).

[15] Martin-de-las-Heras, S., Tafur, D. (2009). Comparasion of simulated human dermal bitemarks possessing threedimensiaonal attributes to suspected biters using a proprietary three-dimensional comparison. For Sci Int, 190, pp.33-37.

[16] Cohrn, K.F., Senn, D.R., Weems, R.A. (2013). Animal Bitemarks in Manual of Forensic Odontology. ( $5^{\text {th }}$ ed.), CRC Press, pp.325-354.

[17] Sweet, D. (1997). Human bitemarks: examination, recovery and analysis. In: Bowers, C.M., Bell, G.L. Manual of Forensic Odontology. ( $3^{\text {rd }} \mathrm{ed}$.). Am Society For Odontol, pp.148-169.

[18] Bernitz, H., Kloppers, B.A. (2002). Comparison microscope identification of a cheese bitemark: a case report. J For Odonto-Stomatol, 20(1).

[19] Pretty, I.A., Sweet, D. (2001). The scientific basis for human bitemarks analyses - a critical review. Sci Justice, 41, pp. 85-92.

[20] Sheabsy, D.R., MacDonalds, D.G. (2001). A forensic classification of distortion in human bite marks. For Sci Int, Oct, 22(10), p.259. 